$$
C O N F=8210+9-25
$$

EFFECTS OF PULSED DUAL-ION IRRADIATIOH OH PHASE TRANSFORMATIONS AND MICROSTRUCTURE IN Ti-MODIFIED AUSTENITIC ALJOY*

\author{
E. H. Lee, V. H. Packan, and L. K. Mansur \\ Metals and Ceramics Division \\ Oak Ridge National Laboratory \\ Oak Ridge, Tennessee 37830
}

$\operatorname{CONE}-321049--25$

DES4 001935

\title{
.. ABSTRACT
}

The influence of pulsed $4 \mathrm{MeV} \mathrm{Ni}$ ion bombardment, with and without simultaneous helium injection, has been explored in a low swelling, Timodified austenitic stainless steel. Irradiations were carried out to $70 \mathrm{dpa}$ at $950^{\circ} \mathrm{K}$; the pulsing frequencies were either $60 \mathrm{~s}$ on/off or $1 \mathrm{~s}$ on/off. Compared to continuous irradiation, pulsing caused a decrease in the interstitial loop diameter at $1 \mathrm{dpa}$, although at higher doses the overall dislocation density was not affected. Pulsing and helium both promoted the stability of MC precipitates and retarded the subsequent $G$ phase formation; in some cases $G$-phase was suppressed and $\eta$ phase formed instear. Small bubble-like cavities were observed to grow into large voids after steady dual beam irradiation to $70 \mathrm{dpa}$. However, this conversion was suppressed by pulsed irradiation to $70 \mathrm{dpa}$ and furthermore the sizes of the small cavities were somewhat reduced. The results are explained in terms of current mechanistic understanding of mean point defect kinetics and the evolution of microstructure and microcomposition during irradiation with superimposed annealing periods.

*Research sponsored by the Division of Materials Sciences, U. S. Department of Energy under contract W-7405-eng-26 with the Union Carbide Corporation.

\section{NOTIGE}

PORTIONS OF THIS REPOAT ARE LLLEGBLE.

it has been reproducet from the best avallable copy to permit the broadest possible avallabillty.
By acceptance of this article. the puolisher or racipient acknowledges the U S. Government's right to perain o ronexclusive. rovaley tree license in and to any copyright covering the article
MASTER<smiles>CC1CC1CC1CC1</smiles>

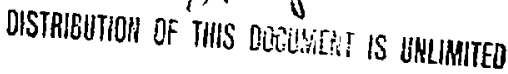




\section{DISCLAIMER}

This report was prepared as an account of work sponsored by an agency of the United States Government. Neither the United States Government nor any agency thereof, nor any of their employees, makes any warranty, express or implied, or assumes any legal liability or responsibility for the accuracy, completeness, or usefulness of any information, apparatus, product, or process disclosed, or represents that its use would not infringe privately owned rights. Reference herein to any specific commercial produst, process, or service by trade name, trademark, manufacturer, or otherwise does not necessarily constitute or imply its endorsement, recommendation, or favoring by the United States Government or any agency thereof. The views and opinions of authors expressed herein do not necessarily state or reflect those of the United States Government or any agency thereof. 
1. INTRODUCTION

A magnetic confinement fusion reactor (MFR) will create an irradiation environment uniike that of existing irradiation facilities in many vital respects including high neutron encrgies, copious helium generation, and discontinuous operation in some projected designs. The last characteristic, intermittent or "pulsed" j.rradiation, could modify the evolution of radiation effects in first wall or other structural components.

A few charged-particle bombardment experinents to explore pulsed irradiation effects have been reported. These have, however, usec either pure metals like $\mathrm{Ni}$ [1-4] and $\mathrm{V}$ [5] or simple alloys such as Fe-15Cr-25Ni [6] and Fe-17Cr-17Ni-2.5Mo [7,8] that do not exhibit phase instability under irradiation. The resulting effects of pulsing were generally found to be subtle, except for "special case" situations of very low damage plus high helium injection [5] or irradiations occurring close to the upper temperature limit for swelling [8].

In standard and modified commercial alloys, however, the development of swelling and related damage effects is complicated by radiation-induced phase changes [9]. A detailed evaluation of the phase behavior in both AISI 316 and a Ti-modified austenitic stainless steel subjected to neutron or ion irradiation or thermal aging has been given by Lee et al. [10]. The present investigaticn explores the influence of pulsed ion bombardment on both microstructure and phase stability in the above-mentioned Ti-stabilized austenitic stainless steel, which has shown notably improved swelling behavior compared to standard 315 stainless steel [11]. 
2. EXPERIMENTAL DETAILS

The approximate composition (wt \%) of the Ti-modified austenitic stainless steel used in this study was Fe-15Cr-15Ni-2Mc-2Mn-1Si-0.2Ti0.05C. Solution-annealed (1373 K) specimen disks 3-mm-diam by 0.35-mm-thick were irradiated at $950 \mathrm{~K}$ in the ORNI dual-ion beam Van de Graaff facility. As in the previous pulsing experiments at this facility $[7,8]$ the instantaneous dose rate was maintained at a low level of $\rightarrow 3 \times$ $10^{-3} \mathrm{dpa} / \mathrm{s}$ in the peak damage region in order to limit temperature variations caused by beam heating to $<4 \mathrm{~K}$ as measured with an infrared pyrometer. Doses from 1 to 70 dpa were attained in this experiment (some prior unpulsed data to $125 \mathrm{dpa}$ is also compared). Bombardments employed either $4 \mathrm{MeV}{ }^{58} \mathrm{Ni}^{++}$ions alone or simultaneous injection of $4 \mathrm{MeV}{ }^{58} \mathrm{Ni}^{++}$ and $0.2-0.4 \mathrm{MeV} \mathrm{He}{ }^{+}$at a ratio of 20 appm He/dpa throughout the central damage region. Synchronized interruption (pulsing) of both beam lines was accomplished with solenoid-actuated beam stops; the periods used are designated "slow pulse" (60 s on/off), "fast pulse" ( 1 s on/off) and continuous bombardment as a control.* Details of the bombardment facility and procedures have been given elsewhere [12].

Following ion bombardment, specimens were electrochemically thinned; first, from the bombarded side to a depth of $0.6 \mu \mathrm{m}$, and then from the back side to perforation. Following transmission electron microscopy (TEM) examination, carbon-film replicas were nade from some foils to capture precipitate particles for analytical electron microscopy (AFM). A JEM $120 \mathrm{CX}$ instrument operated at $120 \mathrm{kV}$ was used for both TEM and AEM.

\footnotetext{
*Just as charged-particle irradiation pernits the simulation of years of riactor damage by hours of bombardment, so too should the pulsing periods be shortened from possible "burn times" of hours to the ruch briefer periods employed here.
} 
Stereo microscopy was used to provide foil thickness estimates from which the values for cavity, dislocation, and precipitate concentrations were deduced. To interpret the $\Lambda E M$ data, the standardless method for determining local compositions outlined by Zaluzec [13] was employed.

\section{RESULTS}

Complete TEM microstructüral data is listed for all these irradiation conditions in Table $I$. The details are described below for each irradiation condition: namely (1) continuous irradiation with no helium injection, (2) $1 \mathrm{~min}$ on/off pulsed irradiation with no helium injection, (3) continuous irradiation with simultaneous helium injection, (4) 1 min on/off pulsed irradiation with simultaneous helium injection, and finally (5) 1 s on/off pulsed irradiation with simultaneous helium injection. An extensive precipitate analysis was performed for the specimens irradiated to 40 dpa. There were noticeable variations in precipitate phase distribution and subtle differences in composition depending upon irradiation conditions, but the identities of precipitate phases were retained irrespective of irradiation conditions. In the following, general aspects of precipitate phases which were comon to all frradiations are described first.

\subsection{Precipitates: General Observations}

The precipitate phases found in Ti-modified 316 are quite numerous and complex. The characteristics of the entire range of precipitate phases and their identification have been covered extensively in Reference 10. Therefore, this description is limited to the three major precipitate 
phases, namely $G, n$, and $M C$, which occur during ion irradiation. The identification has been made by using TEM bright and dark field modes, and by diffraction techniques. Chemical analyses of precipitate phases were performed on extracted particles using the x-ray energy dispersive spectroscopy (EDS) technique. In this experiment particle extraction was done for all alloys irradiated to $40 \mathrm{dpa}$ at the five different irradiation conditions. Although thcre was a tendency toward enriched silicon and nickel content with either continuous irradiation as compared to pulsed irradiation or with increasing dose for a given irradiation mode, these variations were not strong enough to be distinguished unambiguously; they : were encompassed within the scatter band of particle to particle variation. Table II summarizes crystal structures and average measured compositions of each phase. Although G-phase ( $\mathrm{fcc}, \mathrm{Fm} 3 \mathrm{~m}$ ) developed as a thick rod, while rphase (diamond cubic, Fd3m) developed often as a diamondshaped plate, their morphological distinction was not consistently clear. Examination of $x$-ray spectra showed that both G-and rphases were rich in nickel and silicon, and also that each phase was characteristically enriched in one or two other elements. For example, G-phase was characterized by a strong manganese peak, and -phase was rich in chromium and molybdenum. Two different types of MC were found. Large cuboidal particles, which formed during the fabrication process, showed a typical composition of $70 \mathrm{Ti}-30$ Mo (carbon not measured), while smal1 MC particles formed on islocations during irradiation exhibited much less titanium and higher molybdenum with an unusual chromium content (25 Ti-60 Mo-15 Cr). These proportions represent weight percent. Snall MC particles were often clustered on the extraction replica, which, while making analysis easier by producing a strong $x$-ray signal, often produced varying iron and trace 
silicon peaks probably arising from remnant matrix contamination during extraction.

\subsection{Continuous Irradiation Without Helium}

This irradiation established the reference alloy behavior in the absence of pulsing and helium. ihe fluence dependence of microstructural evolution is displayed in Figure 1, left column. Irradiation by $4 \mathrm{MeV} \mathrm{Ni}$ ions initially produced interstitial type Frank loops which eventually unfaulted and interacted to produce network dislocations as fluence increased. The loop density was $4.5 \times 10^{19} / \mathrm{m}^{3}$ with an average diameter of $143 \mathrm{~nm}$ at $1 \mathrm{dpa}$. Increasing the fluence to $10 \mathrm{dpa}$ caused some of the loops to unfault while new loops were still nucleating. Dislocation density saturated at $\sim 2 \times 10^{14} / \mathrm{m}^{2}$ at $70 \mathrm{dpa}$.

Very small MC particles around the edges of dislocation loops after 1 dpa were identified from dark field electron micrographs. There was also an indication of G-phase formation at 1 dpa, but it became more apparent after $10 \mathrm{dpa}$. G-phase particles were often observed inside larger loops. In these regions the losal silicon concentration was expected to be high based on direct observations of segregation to loops [14]. Bot, MC and G-phase were found on or within loops, but their fornation sites were mitually exclusive. MC particles were the dominant phase at lower fluence, indicatirg that the kinetics of MC formation was much faster than that of G-phase. The formation of $\mathrm{MC}$ and G-phase continued with increasing fluence up to $40 \mathrm{dpa}$. Petween 40 and 70 dpa, the :IC particles apparently began to dissolve as the G-phase particles continued to grow and coarsen. At 125 dpa only a few :1C particles remained. The c-phase particle number density reached $-3 \times 10^{20} / \mathrm{m}^{3}$ at 75 dpa but decreased at 125 dpa because of coarsening. 
EDS analysis of the G-phase composition showed that there was a tendency for the concentrations of $\mathrm{Ni}$ and $\mathrm{Si}$ to increase as the fluence increased from 40 to $125 \mathrm{dpa}$. The volume fraction of G-phase was estimated to be about $4 \%$ at 125 dpa. Since the G-phase contained $45 \% \mathrm{Ti}$, a total of -0.2 wt $\% \mathrm{Ti}$ is thought to have been removed as G-phase precipitated from the system, which leaves less than 0.05 wt \% $\mathrm{Ti}$ in solution. This would contribute to MC dissolution when Gaphase becomes dominant. A few $\pi$ phase particles were also found, but these comprised only a negligible fraction in comparison to G-phase. Finally, no cavities were found in the absence of helium injection up to $125 \mathrm{dpa}$, indicating that helium is essential for cavity nucleation in this alloy.

\subsection{Slow Pulsed Without Helium}

These specimens were irradiated with a pulsed beam cycle of 1 min on/l min off without helium injection. Two major differences were found in comparison to the non-pulsed case. First, pulsing restricted the growtn of loops, and second it enhanced the stability of MC particles as can be seen in Figure 1. The average loop diameter was $68 \mathrm{~nm}$ at 1 dpa which is about half the diameter of that in the non-pulsed case (143 nm), On the other hand the loop density increased with pulsing both at 1 and 10 dpa (see Table I). At 10 dpa the loop diameter displayed a bimodal distribution indicating a new moulation of secondary loops while loops formed earlier were unfaulting or growing. At 40 dpa loops were completely unfaulted. At higher fluences the dislocation density saturated at $\sim 1 \times$ $10^{1 i_{4}} / \mathrm{m}^{2}$, similar to the level. of the non-pulsed case. 
Precipitate evolution in pulsed specimens was similar to that in the non-pulsed case except for the enhanced stability of MC phase with a corresponding inhibition of G-phase, noticeabie at $40 \mathrm{dpa}$. There were no discernible differences in $M C$ composition among particles formed under pulsed or non-pulsed conditions. The G-phase composition, however, showed a slight reduction in silicon in the pulsed case. Cavities were not found in this no-helium case either."

\subsection{Continuous Irradiation with Helium}

These specimens were irradiated with simultaneous helium implantation at a rate of $20 \mathrm{appm} H e / d p a$. This irradiation condition provides a reference for the effect of helium on the evolution of various microstructural components. The development of the dislocation microstructure revealed a progression very similar to the case of no helium and no pulsing. However, the mixture of phases, specifically MC and G-phase, as well as the cavity formation process, was greatly altered by helium injection (Figure 2, left column). The loop density was $7.4 \times 10^{19} / \mathrm{m}^{3}$ and their mean diameter was $128 \mathrm{~nm}$ at 1 dpa. As damage continued, loops unfaulted, and dislocation density saturated at $-2 \times 10^{14} / \mathrm{m}^{2}$ at $70 \mathrm{dpa}$.

The stability of $M C$ was enhanced by helium injection to a much greater extent than by pulsing. MC formation became very obvious at 10 dpa and particles coarsened at 40 dpa into stringers of $M C$ along dislocations or into a branched dendritic morphology along, [100] directions. Virtually all of the $M C$ particles were associated with one or more small 
cavities or bubbles. G-phase was greatly suppressed up to $40 \mathrm{dpa}$, but began to dominate beyond $70 \mathrm{dpa}$, concurrent with MC redissolution. Although not observed at $1 \mathrm{dpa}$, small visible cavities (avg. diam 3-4 nm) were found at higher doses. The cavity density increased with dose in the order of $1.6,6.7$, and $30 \times 10^{21} / \mathrm{m}^{3}$ at 10,40 and $70 \mathrm{dpa}$, resfectively. At 70 dpa a binodal cavity size distribution had developed, including both $i$ :iformly distributed small cavities and voids (avg. diam $41 \mathrm{~nm}$ ) which were mostly associated with G-phase particles (Figure 2, left bottom). The void density was about $3.5 \times 10^{20} / \mathrm{m}^{3}$ producing about $2 \%$ swelling.

\subsection{Slow Pulsed with Hẹlium}

This combination of irradiation conditions had the greatest effect on microstructural evolution, as compared to the reference condition. Referring to Figure 2, four major highlights can be noticed:

(1) restricted loop growth, (2) suppressed cavity growth, (3) enhanced MC stability, and ( 4 ) a shift in the dominant phase stability from $G$ to $\eta$. Loop growth was restricted severely by pulsing alone and further refinement was seen when helium was injected. Loop diameters averaged 45 nn at 1 dpa which was -3 times smalier than those of non-pulsing cases.

Dislocation density, however, saturated again at about $2 \times 10^{14} / \mathrm{m}^{2}$ at T0 dpa. Enhancement of MC stability and suppression of cavity growth were concurrent phenomena. MC particles apparently nucleated around loops in concentric fashion as the loops grew ifigure 2, see also [9]). Helium bubbles again were found at $\mathrm{MC}$ interfaces. At 10 dpa MC particles were already prevalent, however no bubbles were visible - they probably existed but were too small to be seen as a result of fine dispersion over the large total area of $\mathrm{MC}$ particle/matrix interfaces. At $40 \mathrm{dpa}: \mathrm{C}$ formation appeared to have peaked and most bubbles were probably still too small to image except for a few bubbles at the large precipitate interfaces. At 70 
dpa lic particles seen to have coalesced and reconstructed their morphology in a dendritic fashion along [100] directions. Cavities were also observed at a density of $1.4 \times 10^{22} /$ in $^{3}$ with average diameter of $3.3 \mathrm{~nm}$. Post of the cavities were located in the matrix or at MC particles with some on the eta-phase/matrix interfaces. Remarkably, cavity conversion to rapidly-growing voids was totally suppressed up to $70 \mathrm{dpa}$, producing less than $0.03 \%$ swelling. This should be compared with the $2 \%$ swelling produced during continuous dual-beam irradiation and the same dose.

Quantitative $x$-ray EDS analysis of precipitates indicated that the small MC particles were a Cr-rich $\mathrm{T} i$ and Mo compound and, strikingly, most large precipitates were found to be $\pi$-phase instead of G-phase. A few Gphase particles were also found but were silicon-poor. The volume fraction of large precipitates, namely $\pi$ phase in this case, was greatly reduced even at 70 dpa because of the combined effect of pulsing and helium injection.

\subsection{Fast Pulsed with llelium}

Fast fulsing with helium injection produced two major microstructurai modifications: (1) loop size was still further reduced and (2) again the dominant phase shifted from $G$ to $n$-phase. The average loop diameter in this case was $24 \mathrm{~nm}$ at $\mathrm{l}$ dpa, the smallest among the five experimental conditions. Figure 3 contains observations of results produced by fast pulsing. As fluence increased loops unfaulted, and dislocation, bubble, and precipitate distributions approached those of the non-pulsing case, as can be seen by comparing Figures 2 and 3 . However, EDS analysis again indicated that most large precipitates at 40 dpa were n-phase instead of G-phase. At $40 \mathrm{dpa}$, the highest dose attained with fast pulsing, most MC particles were linked together and nphase particles were numerous. 
4. LISCUSSION

\subsection{Dislocation Loops}

Considering the damage phenomena in their order of appearance with increasing fluence brings one first to the dislocation loop microstructure at $1 \mathrm{dpa}$. At the very start of an irradiation the volume-averaged interstitial concentration $C_{i}$ abruptly increases, culminating in early, profuse nucleation of interstitial loops. The average interstitial concentration thereupon declines, sharply at first and then gradually, to a steady-state value that is significantly lower than, but related to, the average matrix vacancy concentration $C_{v}$ by the relation $\bar{Z}_{v} D_{v} C_{v}=\bar{Z}_{i} D_{i} C_{i}$. In this relation the $D^{\prime}$ 's are diffusion coefficients and the $\overline{Z^{\prime}}$ 's are capture efficiencies for the respective point defect species averaged over all point defect sinks. There follows an attrition of the interstitial loops when the slow-moving vacancies begin to reach them. Yet the fact that some loops survive to be observed indicates that some portion of the vacancies are hindered from reaching the loops, perhaps by being trapped at impurities and other lattice inhonogeneities or by self-clustering into immobile aggregates.

With pulsing, the commencement of a beam-off period causes the interstitial concentration in the matrix to plumnet but the vacancy supersaturation persists for a "lifetime" of the order 0.2-1.0 s fur the temperature and measured sink (loop) densities of this experinent.* Thus

*For the Five irradiation nodes of Table I at 1 dpa, the calculated vacancy lifetime values $\tau_{v}=\left(D_{v} s_{v}\right)^{-1}$ were $0.29,0.27,0.19,0.68$, and $1.04 \mathrm{~s}$ respectively, using values of $D_{\mathrm{v}}^{O}=1.4 \times 10^{-6} \mathrm{~m}^{2} \mathrm{~s}^{-1}$ and $\mathrm{E}_{\mathrm{v}}^{\mathrm{m}}=1.3 \mathrm{eV}$ in the calculation. The sink strength $S_{V}$ was here taken as the dislocation length per unit volume, $\mathrm{L}$, and $\mathrm{D}_{\mathrm{v}}=\mathrm{D}_{\mathrm{v}}^{\mathrm{O}} \exp \left(-\mathrm{E}_{\mathrm{v}}^{\mathrm{m}} / \mathrm{kT}\right)$. 
there ensues a brief period of unopposed vacancy "nibbling away" at the interstitial loops. With the next beam-on interval comes a new burst of loop generation and the cumulative effect of such irradiation pulses ought to be the net refinement - more but smaller loops - which was clearly observed.

The addition of helium (without pulsing for the moment) adds a potent impurity to retard and trap vacancies. The restricted vacancy mobility should result in a larger number of surviving interstitials in loops; the additional loops - small ones - would be roflected in a reduced average loop size. This hypothesis was borne out by the measured loop sizej: distributions from which were calculated the mean values of Table I. Contributing further to the reduced loop size could be the influence of those helium and $M C$ clusters located on the interstitial loop peripheries. Such clusters could be impediments to loop growth by degrading the loops' capture efficiency for point defects.

Pulsing added to helium injection contributed no significant further effect on the interstitial loop densities, but the loop shrinkage caused by vacancy absorption during the first second or so of beam-off time seems to have continued unabated, further reducing the average loop size. The relative magnitade of this "erosion" effect ought to be greater the more times it can occur. Thus fast ( 1 s) pulsing exhibited the smallest loop size of all. These explanations have focused more on the loop dianeters than on the concentration data, both because the diameters are inherently easier to establish accurately (no foil thichess value is involved) and because it was the diameters that varied the most for different irradiation modes. 
These considerations are only clear-cut at low dose; at higher doses the interstitial loops unfaulted, impinged, and grew into dislocation network while at the same time precipitates and (with heiium) small cavities developed significantly. The mutual interactions of these various types of sinks are complex; what we observed is that the subsequent dislocation density was generally insensitive to helium or pulsing conditions.

\subsection{Precipitates}

Unirradiated specimens of this material given the same thermal history as the bombarded specimens contain nainly some coarse "thermal MC" precipitates formed during fabrication and aging. In the early stages of $\mathrm{Ni}$ ion irradiation at $950 \mathrm{~K}$, widespread precipitation of fine $\mathrm{MC}$ particles occurs in close associatiun with the newly-formed interstitial loops. However, even though $M C$ is thermally stable, it is only metastable under irradiation because displacement cascades continually knock molybdenum, titanium, and carbon atoms from $\mathrm{k}$ into the matrix and knock matrix atons into the precipitates. Once dispersed, the MC constituents can be incorporated within the growing $G$ phase particles $[9,10]$. As irradiation proceeds, radiation-induced silicon and nickel atom segregation results in the formation and growth of silicon- and nickel-rich $G$ phase. Since the $G$ phase also incorporates Mo and $\mathrm{Ti}$, it gradually supplants $\mathrm{MC}$. (G-phase is alin subject to cascade dissolution; however, the radiation induced segregation of G-phase-formers, especially $\mathrm{Ni}$ and $\mathrm{Si}$, favors G-phase.)

Pulsed irradiation should in the first place give rise to enhanced itC formation because it was shown to generate more dislocation loops at low dose, which would thus provide more $M C$ nucleation sites. But the major effect is probably the influence irradiation interruptions have on the $\mathrm{MC}$ vs $G$ phase balance. During the beam-off intervals, MC as the tremazi stable phase could partially reconstitute itself, absorbing the vacancies 
it especially needs and posstbly reabsorbing sone of the knocked-out molybdenum, titanium, and carbon atoms. At the same time silicon and nickel back-diffusion into the matrix during the beam-off periods would undo the effects of solute segregation and clearly work against the growth of $G$ phase. So initially the effect of pulsing ought to show up as enhanced $M C$ stability and retarded $G$ phase formation (as observed). But the ratas of atom movement are also important. The flow of atoms both inco and out of $M C$ particles is relatively rapid, as is the influx of atoms at $G$ particles growing during irradiztion $[9,10]$. But the thermal dissolution process of $G$ phase (in beam-off times) is slower [9,10]. This sluggish dissolution of G-phase has been established in postirradiation annealing experiments $[2]$. Thus $G$ phase formation eventually stil] prevails.

If helium is added in a dual beam (continuous) irradiation, it acts to stabilize MC by relieving particle/natrix misfit strain and by providing more sites for MC nucleation. The typical iC particle has a large volune misfit ( $\sim 83 \%)$; thus the $\mathrm{MC} /$ matrix interface would be a potent trap for helium-vacancy pairs [15]. The small heliun-stabilized cavities also provide more sites for point defect recombination, thus helping to reduce long-range point defect and solute transport. This should effectively retard radiation-driven processes like solute segregation that in turn affect $G$ phase formation by lowering the point defect fluxes to sinks. G phase would also be delayed by a "solute dilution" effect: the silicon-nickel segregation processes irvolving a fixed number of segregating atoms take place at a larger number of sites owing to the influence of heliun. The result should be again nore $M C$ and less $G$ formation, as we ubserved, because of a lower buildup of nickel and silicon, atons necessary for G-phase, at each site (see also [16́]). 
The combination of both pulsing and helium conditions seems to have so thoroughly restricted the silicon and nickel segregation processes, vital to the formation of $G$ phase, that $n$ phase was formed instead. Eta is an irradiation-enhanced rather than induced phase with only half the silicon and nickel content of G (Table II). Other consistent observations were that more $M C$ was retained and that the few observed $G$ particles had a reduced silicon content.

Earlier it was seen that pulsing frequency had a reasurable effect on dislocation loops at $1 \mathrm{dpa}$ : fast pulsing gave the smallest mean loop diameter. By contrast this 1 s on/off pulsed irradiation did not enhance MC formation at $10 \mathrm{dpa}$. Evidently the kinetics of MC thermal reconstitution are not fast enough to replenish the cascade-eroded MC during a $1 \mathrm{~s}$ off period. Consistent with this, in the mal anneal experiments $[9,17]$ small MC has been observed to appear in aging periods on the order of about 2 min at $\sim 950 \mathrm{~K}$. Nevertheless there was still a substicution of $n$ phase for $G$; in fact, there was more $n$ than for $60 \mathrm{~s}$ pulsing, probabıy due to the lower $\mathrm{MC}$ fraction. Thus, the suppression of G-phase by pulsing plus helium was still in effect.

\subsection{Small Cavities and Voids}

Cavities are observed in this material only if helium is present. Depending upon the amount of helium present in a small cavity, there is a certain equilibrium size, $r e q$, that it would maintain, in the abserce of irradiation, as a gas-stabilized bubble [18]. However, under irradiation 
with a net vacancy influx, such a cavity will grow. Up to a critical size, $\mathrm{r}^{\text {crit, }}$, this growth is gradual and dependent on helium influx; the cavity only accepts vacancies if helium atoms are added also. A cavity below critical size will tend during irradiation to hold at i steady-state size, $r^{s s,}$ where $\mathrm{r}^{\mathrm{eq}}<\mathrm{r}^{\mathrm{ss}}<\mathrm{r}^{\mathrm{crit}}$, and this can gradually increase as helium is continual1y added to the system [18].

Above the critical size, the vacancy to helium acceptance ratio increases abruptly and the cavity can experience "bias-driven grcwtn" as a void. The magnitude of $\mathbf{r}^{\text {crit }}$ is extremely sensitive to the gas content, the bias, the surrounding point defect sink microstructure and irradiation temperature. Sensitivity of cavity growth to temperature, sink strength and bias are drastically reduced with increasing gas pressure in the cavily.

Pulsed irradiation consists of a succession of irradiation periods interspersed by thernal annealing periods. Juring the on-times, a cavity rill have some steady-state size less than a finite rcrit, but when the beam goes off, the critical size becomes effectively infinite and the cavity itself tends to shrink back toward the thernal equilibrium size req. One would expect, therefore, to observe that (1) the appearance of large voids should be postponed, and (2) the average size of the small cavities hovering above $r^{e q}$ and below $r^{c r i t}$ should be smaller than for continuous irradiation. These predictions are consistent with the data in Table I. In that data, there also appears to be a trend for the small. cavity population fron $60 \mathrm{~s}$ pulsing to have a smaller mean diameter than their fast-pulsed counterparts. It seems likely that this effect reflects the finer dispersion of $\mathrm{MC}$ particles for slow pulsing, which in turn would impose a finer scale of cavity formation. 
The observations that void swelling is retarded up to 70 dpa by pulsed irradiation in this material does not mean that swelling will remain low indefinitely. The eventual appearance of voids after the precipitate microstructure has transformed to large $G^{-}$or -phase particles may presage a more rapid than normal growth for the voids. The point defecl collector mechanism has been shown to explain the rapid growth of voids which are associated with such large precipitates $[17,19]$.

\subsection{Sumnary}

Our preliminary analysis Indicates that current understanding of mean point defect kinetics and the evolution of microstructure and microcomposition can be extended to explain these results. The effects of pulsing can be interpreted as the results of periodic anneals only, rather than as any peculiarities in point defect concentration profiles induced by pulsing. This is consistent with expectations fron recent theoretical work [20] where it was found that intrinsic local "pulsing" by cascadeinduced point defect concentration fluctuations that occurs during steady irradiations is so large and frequent that any changes that could be produce: by beam interruptions would be rejatively insignificant. Interstitial loops are created very early in the irradiation. Observed interstitial loops are the results of further growth through the competing processes of interstitial accumulation and vacancy erosion. Heliun ties up more vacancies in the matrix and thus allows enhanced accumulation of interstitials. Pulsing periodically provides the initial burst of interstitial loop nucleation and results in a finer dispersion of loops. Pulsing also delays the onset of bias driven cavity swelling by providing annealing periods for cavity shrinkage. When heliun is injected with or 
without simultaneous pulsing, there is formed a population of small cavities hovering below their critical radius for bias-driven growth and above the equilibriura radius corresponding to the number of contained gas atoms. However, by providing regular intervals of annealing, pulsed irradiation results in these small cavities being closer to the equilibrium size. Both pulsing and helium injection change the stability of prases and result in different mixtures of coexisting phases. Helium injection favors iC phase, a thermal phase, over the radiation induced G- or radiation enhanced $\pi$ phases. This is brought about in part by the above mentioned greater number of dislocation core nucleation sites resulting from helium injection as well as by the accommodation of the large íc strain field by helium-producef cavities. In addition both $G$ and $n$ phase are enriched in nickel and silicon by radiation induced segregaiion at sinks. Because helium injection produces more sinks, and the number of nickel and silicon atoms is fixed, it follows that nickel and silicon segregation are reduced by dilution. Pulsing also enhances MC over G- and Tphases by providing periods of thermal reconstruction (without cascade dissolution) to restore the MC phase. These same periods also tend to retard $G$ and $\eta$ phase by allowing the nickel and silicon gradients to relax. During pulsing $n$ phase is favored over $G$ phase as the minor phase because it requires less nickel and silicon.

\section{CONCLUSIOHS}

Single and dual ion irradiations, continusus and pulsed, of a svelling-resistant and phase unstable alloy have resulted in the following observations:

$\checkmark$ Helium increased the concentration of interstitial loops and sonewhat reduced their sizes at 1 dpa. 
- Pulsed irradiation had a strong refinement effect on the 1 dpa loop sizes; fast ( $1 \mathrm{~s}$ on/off) pulsing gave the smallest loop size.

$\Rightarrow$ After transformation from loops to network, the dislocation density was not sensitive to pulsing or helium.

? Pulsing enhanced the extent of $M C$ precipitation and retarded the formation of $G$ phase which later supplants it.

- Helium also favored $M C$ retention and restricted $G$ phase development.

a Pulsing together with helium gave further MC enhancenent and shifted phase stability conditions from $G$ phase to the less siand Ni-rich $n$ phase.

$\rightarrow$ Cavities were observed only for dual-beam bombardment.

- Sub-rritical-size cavities had a smaller mean size due to pulsing.

- Formation of large voids was suppressed by pulsed irradiation fo: Lioses up to $70 \mathrm{dpa}$.

The results are explainable in light of current theory for radiation damage structure and phase stability. During the beam-off periods it appears that interstitial loops are vulnerable to erosion by unopposed vacancy fluxes, the phase stability criteria reverse to favor $M C$ reconstruction and nickel/silicon thermal desegregation which retards $G$ phase, and small cavities regress toward their equilibrium sizes as bubbles. These observations and their suggested explanations are useful in understanding defect inechanisns as well as pertinent to the possible usefulness of such conplex alloys in a sequential-burn type of fusion reactor.

\section{ACKNOWLEDGMENTS}

The authors would like to thank $M$. B. Tewis and S. W. Cook for carrying out the ion bombardments, Judy Young for manuscript preparation, and L. I. Horton and P. J. Maziasz for constructive technical review. 
References

1. J.A. Sprague and F. A. Smidt, Jr., "Electron Microscopy of Voids in Ion Bombarded Nickel," pp. 25-33 in Coonenative Rarixtion Pffects

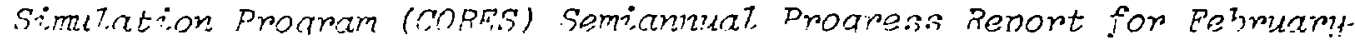
Octoher 1.77?, Naval Research Laboratory Memorandum Report 2555 (ed. by L. F. Steele and E. A. Wolicki), Washington, DC, February 1973.

2. J. A. Sprague, and F. A. Smidt, Jr., "The Effect of Beam Scanning on Nickel-Ion Damage in Nicke1," pp. 27--36 in CoPnS Serriannur7, Proaress Renort for lovember 1972"Anmi, 1973, NRL Memorandum Report 2629, August 1973.

3. A. Taylor, D. I. Potter, and H. Wiedersich, The Fffects of Pulsed, Irratiation on Voi. Microstmetures in Nicket, Argonne National Laboratory report ANL/FPP-79-3 (1979).

4. J. I. Brimhal1, L. A. Charlot, and E. P. Simonen, "Effect of Pulsed Irradiation on Void Swelling in Nickel," J. Nuc?. Mater. $103 \& 104$ (1981) pp. $114 i-50$.

5. D. Kaletta, "The Microstructure of Vanadium Implanted with 2-MeV Helium Ions under Pulsed Conditions," J. Nucl. Mater. 85\&86 (1979) pp. $775-79$.

6. R.W. Powell and G. R. Odette, "The Effect of Pulsed HVEM Irradiation on Hicrostructure Evolution in a Simple Fe-Ni-Cr Alloy," .T. Muct. Mater. 85\&86 (1979) pp. 695-99.

7. N. H. Packan, "Effect of Pulsed Dual-Ion Irradiation on Microstructural Developnent," T. Nucl. Mater. $103 \& 104$ (1981) pp. 1029-34.

8. K. Miyahara, N. H. Packan, and N. Igata, "The Effect of Pu1se Irradiation on Void Swelling of a 'Pure' 316 Stainless Steel," Tffect of Ratiation on interials: Eleventh Conference, ASTM STP 782, H. R. Brager and J. S. Perrin, eds., American Society for Testing and Materials, 1982, pp. 941-52.

9. A. F. Rowcliffe and E. H. Lee, "High Temperature Radiation Damage Phenomena in Complex Alloys," .T. Mlect,. Mrtepr.108\&109 (1982) pp. 306-13.

10. F. H. I.ee, P. J. Maziasz, and A. F. Rowcliffe, "The structure and Composition of Phases Occurring in Austenitic Stainless Steels in Thermal and Irradiation Environments," pp. 191-218 in Phase stahititu Anrind Irpairintion, I. R. Holland, L. K. Mansur, and D. I. Potter, eds., AIMIF, 1981. 
11. E. H. Lee, A. F. Rowcliffe, and E. A. Kenik, "Effects of Si and Ti on the Phase Stability and Swelling Behavior of AISI 316 Stainless Steel," J. Mucl. Mater. 83 (1979) pp. 79-89.

12. M. B. Lewis, N. H. Packan, G. F. Wells, and R. A. Buh1, "Improved Techniques for Heavy-Ion Simulation of Neutron Radiation Damage," Mue?. Instruments ant Methods 167 (1979) pp. 233-47.

13. N. J. Zaluzec, Introluction to Analutical Plectron "ficrosconu, J. J. Hren, J. I. Goldstein, and D. C. Joy, edi., Plenum Publ. (1979) p. 121 .

14. E. A. Kenik, Seripta Met. 10 (1976) p. 733.

15. P. J. Maziasz, "Helium Trapping at Ti-Rich MC Particles in Ti-Modified Austenitic Stainless Steel," pp. 477-92 in Phase Strhit,itu Huring Irratiation, J. R. Holland, L. K. Mansur, and D. I. Potter, eds. AIME, 1981 .

16. P. J. llaziasz, "Some Effects of Increased Helium Content on Void Formation and Solute Segregation in Neutron Irradiated Type 316 Stainless Steel," J. Mucl. Mater. $108 \& 109$ (1982) 359-84.

17. E. H. Lee, A. F. Rowcliffe, and L. K. Mansur, "Precipitate and Cavity Formation in Austenitic Stainless Steels during Irradiation," $J$. Nuc7. Mater. 103\&104 (1981) pp. 1475-80.

18. A. Hishinuma and L. K. Mansur, "Critical Radius for Bias-Driven Swelling - A Further Analysis and Its Application to Bimodal Cavity Size Distributions," "Toumat. Of Nuc',ear Material,s (submitted).

19. L. K. Mansur, "Theoretical Evaluation of a Mechanism of Precipitate-Enhanced Cavity Swelling during Irradiation," P'?ir.oson'. Mra. A 44 (1981) pp. 867-77.

20. L. K. Mansur, W. A. Coghlan, and A. D. Brailsford, T. Muc T. Mater. 85886 (1979) 591 . 
TABLE T

Microstructural Data of Ti-Modified 316 After Various Ion Irradiations

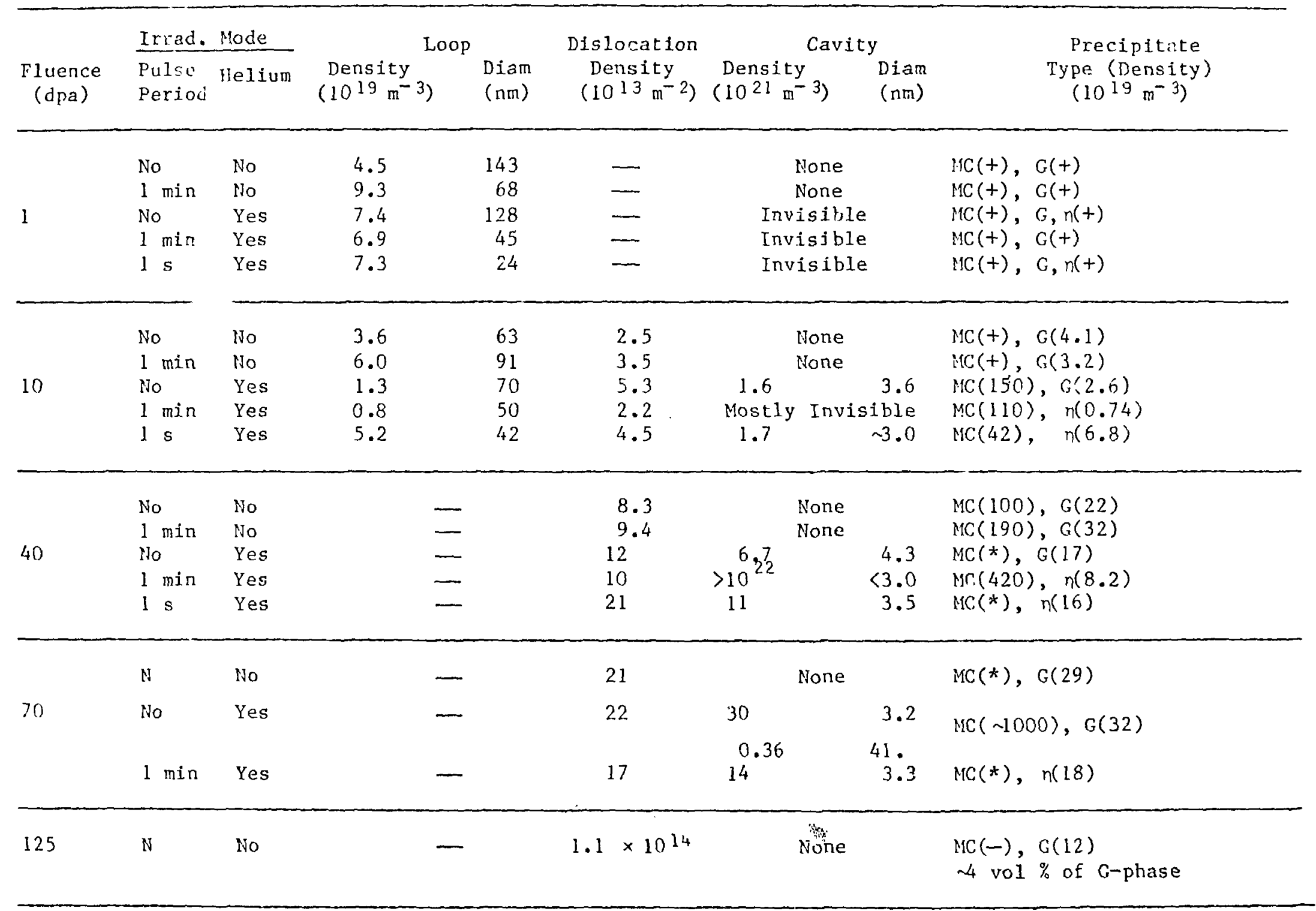

$(+)=$ indeterminant but detectable

$(*)=$ connected or coarsened

$(-)=$ few 
TABLE II

Structures and Compositions of Major Phases Which Occur in Ion Irradiated Ti-Modified Austenitic Stainless Steel

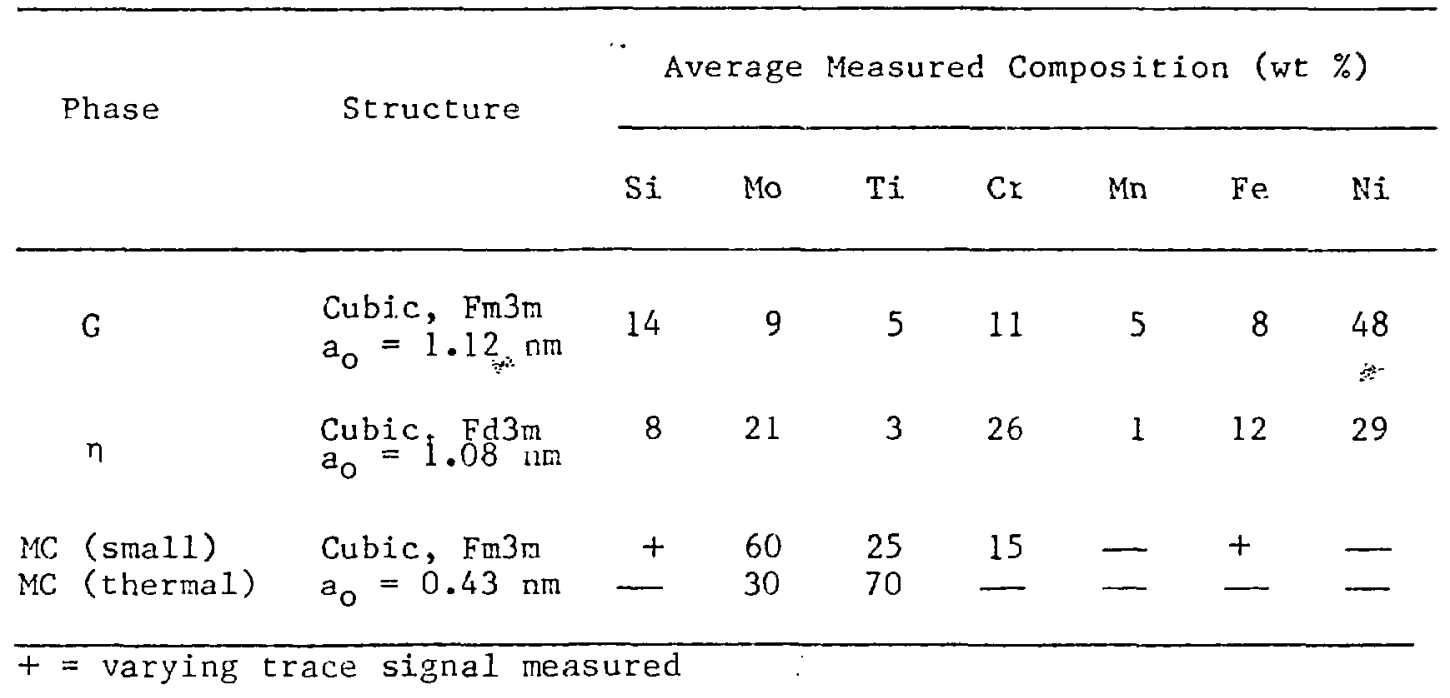




\section{FIGURE CAPTIONS}

Figure 1. Development of damage structure and precipitates with dose in Ti- modified austenitic stainless steel irradiated with $4 \mathrm{MN}$ ivi ions (no $\mathrm{He}$ ) at $950 \mathrm{~K}$ for continuous irradiation (left) and $1 \mathrm{~min}$ on/off pulsed irradiation (right).

Figure 2. Development with dose of damage effects in Ti-modified austenitic stainless steel subjected to dual-ion bombardment ( 20 appm He/dpa) at $950 \mathrm{~K}$ for continuous irradiation (left) and $1 \mathrm{~min}$ on/off pulsed irradiation (right).

Figure 3. Development of radiation damage at $950 \mathrm{~K}$ in dual-ion bonbarded Ti-modified austenitic stainless steel for fast pulsed irradiation ( $s$ on, 1 s off). 

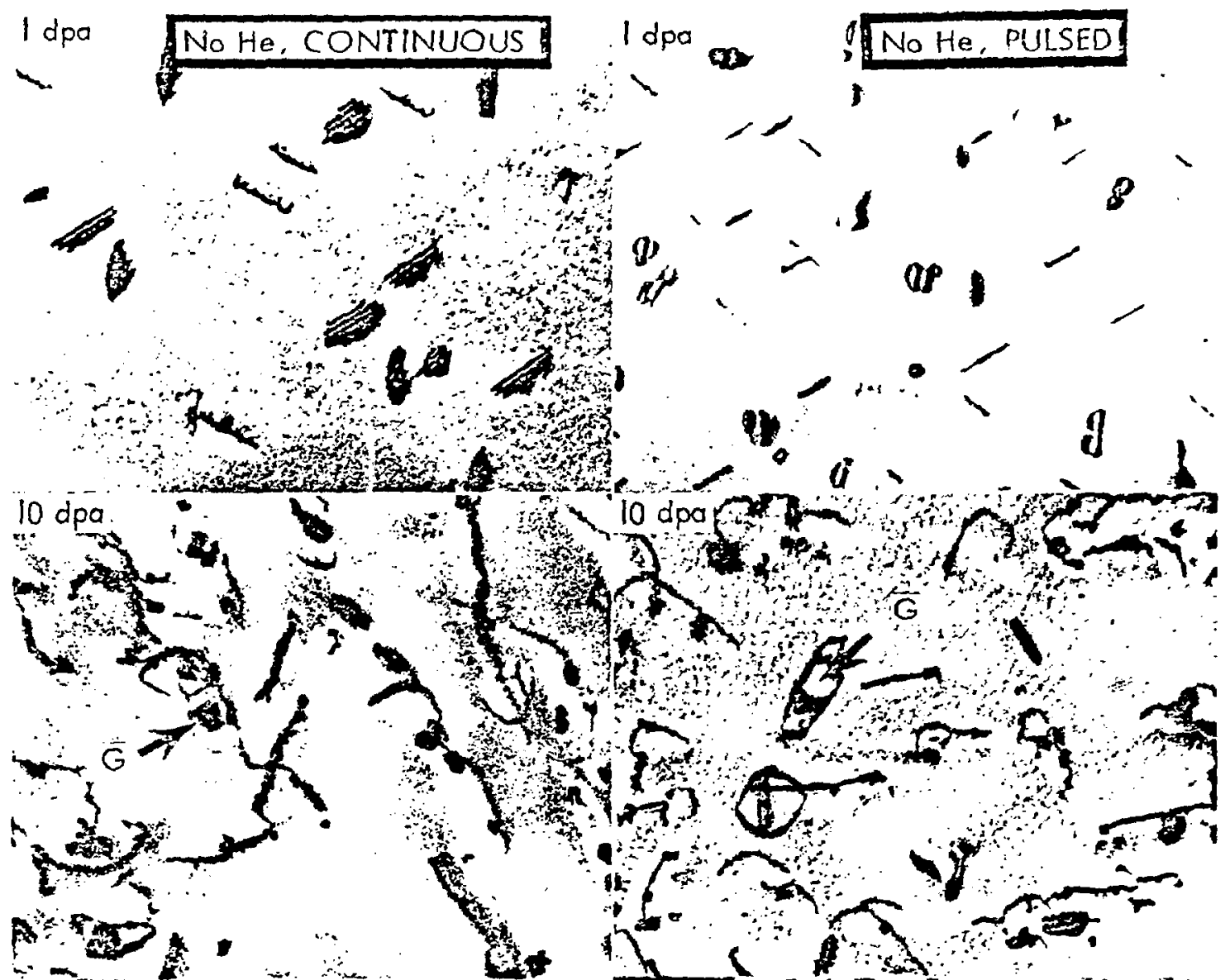

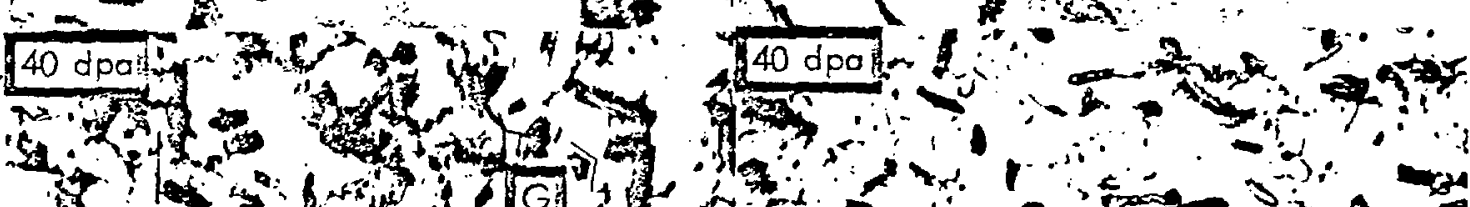
a

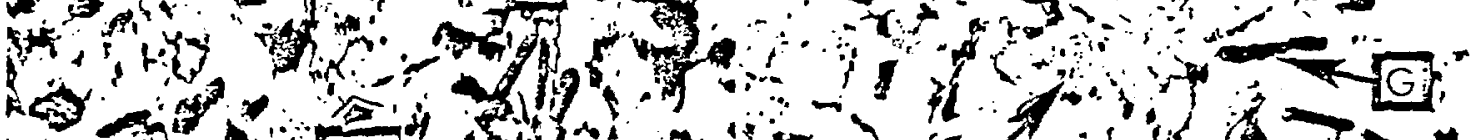

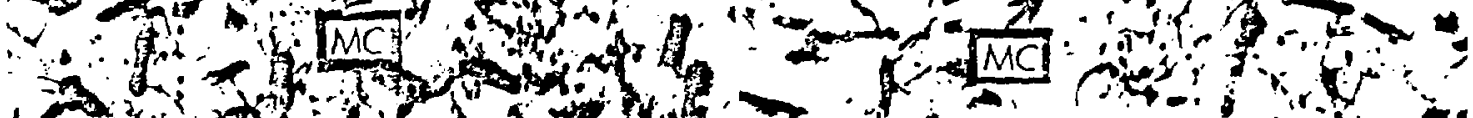

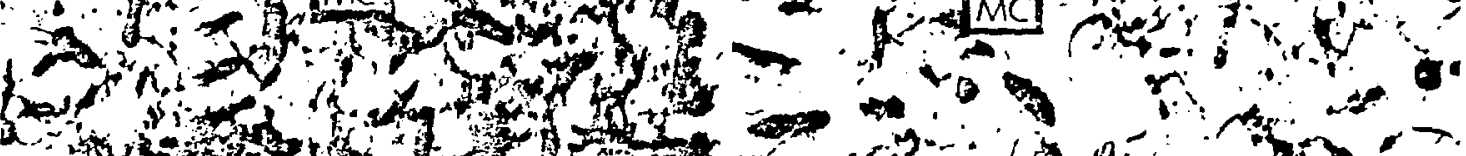
(2)

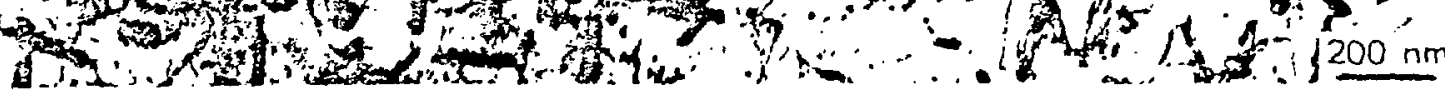




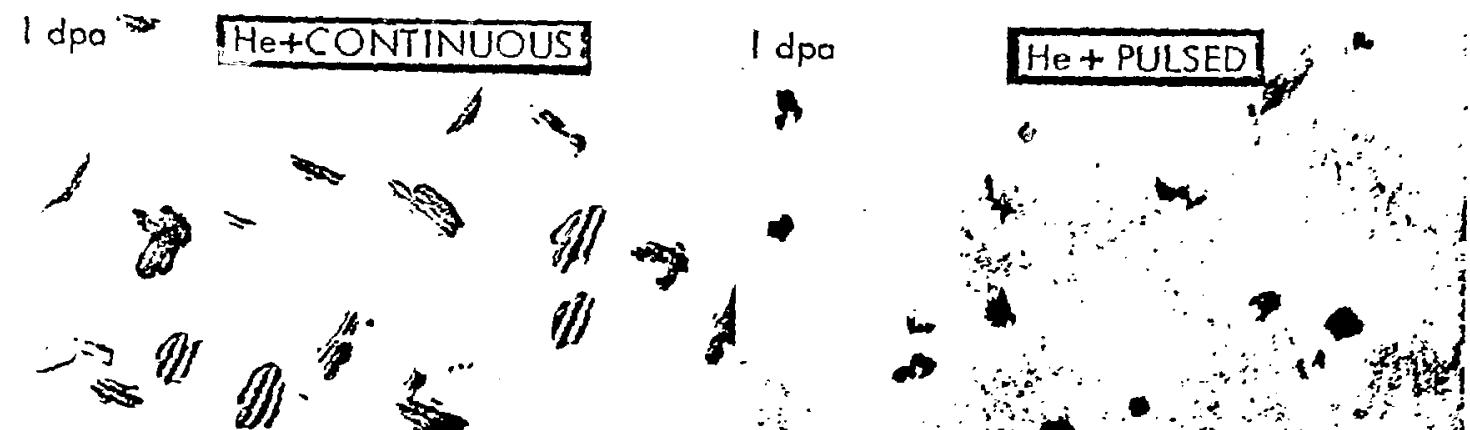

$10 \mathrm{dpa} \mathrm{y}^{\prime} \mathrm{x}$

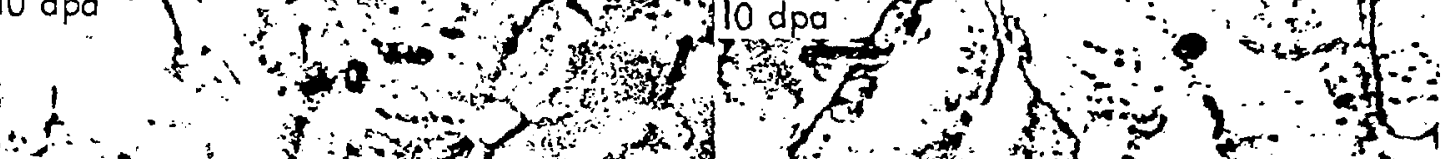

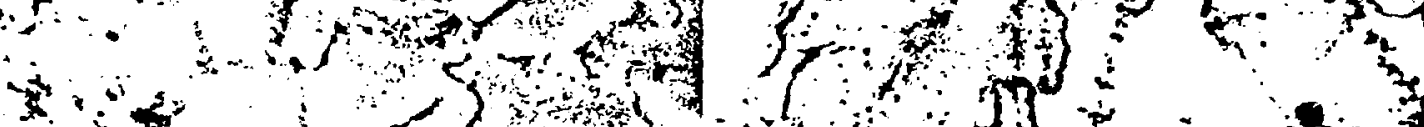

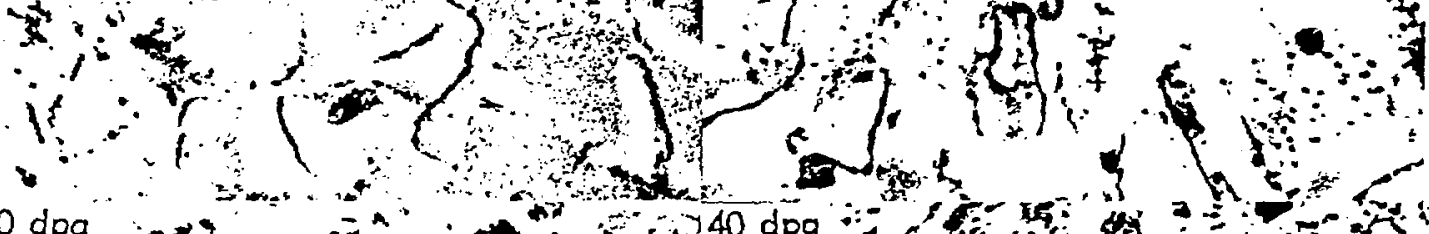

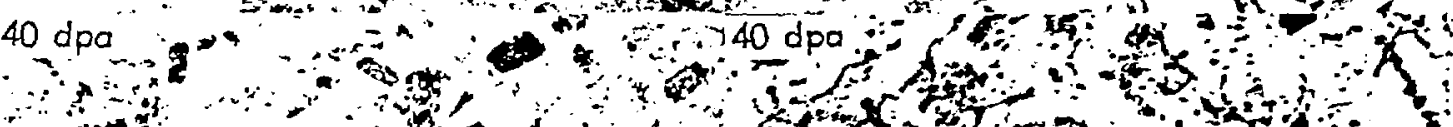
$\therefore$ a

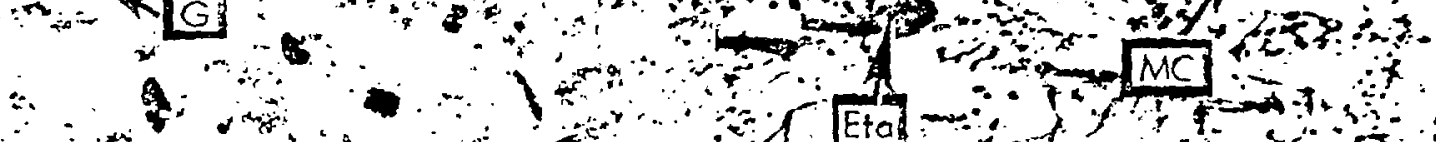
$\therefore$ and

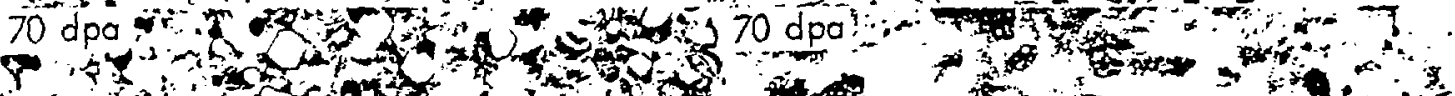

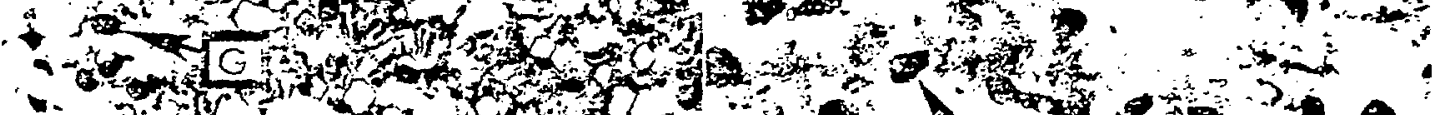
1)

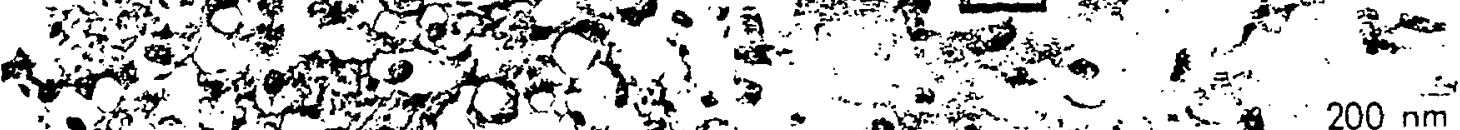

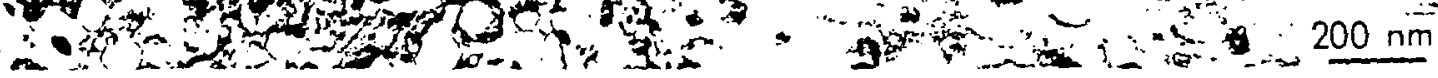




\section{ORNL-PHOTO $3643-8 \%$}

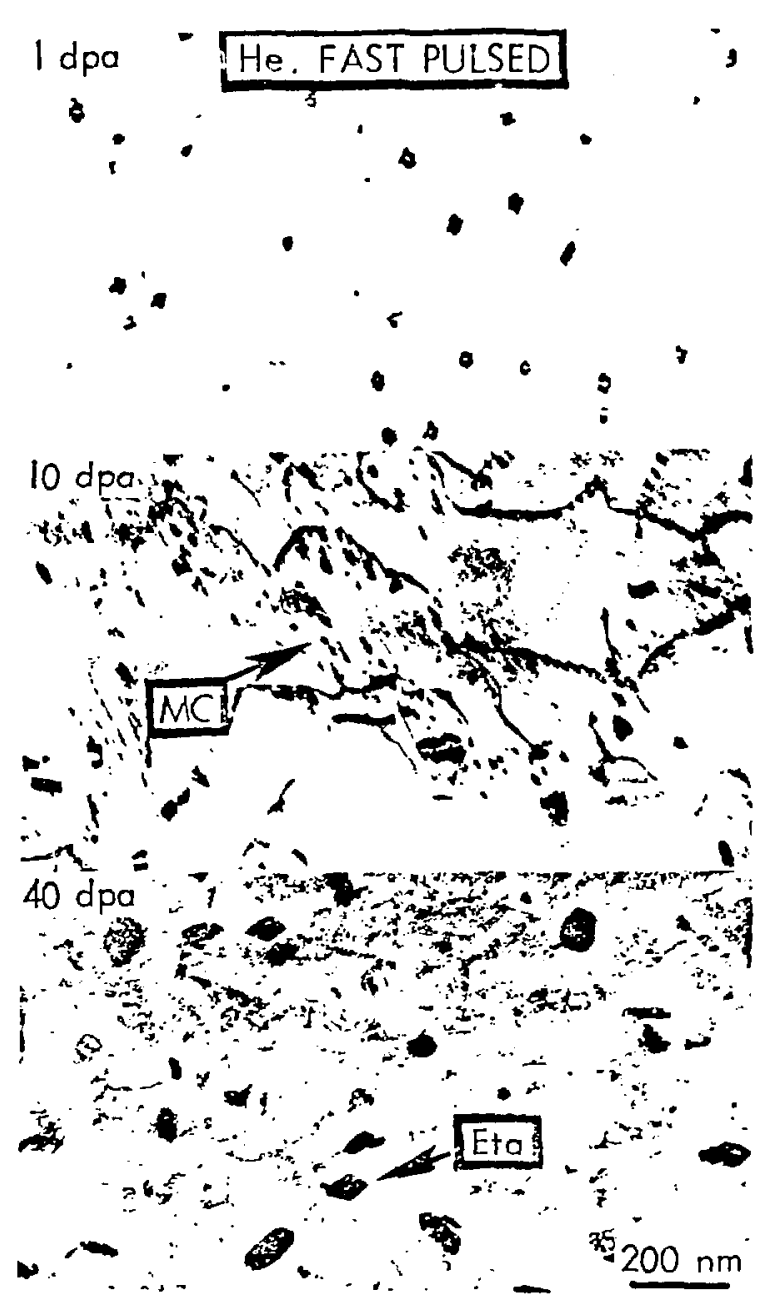

